\title{
Educação das Relações Étnico-Raciais nas instituições escolares
}

\section{Education of Ethnic-Racial Relations in Schools}

\author{
Petronilha Beatriz Gonçalves e Silva*
}

\begin{abstract}
RESUMO
O presente artigo realiza revisão de 38 artigos, 7 teses e 51 dissertações da área de educação publicados entre 2003 e 2014 e que tratam do tema educação das relações étnico-raciais em instituições educacionais. Os escritos, em sua maioria, registram resultados, experiências de educação em estabelecimentos de ensino, bem como considerações, avaliações, reflexões, sugestões no que diz respeito à educação étnico-racial. As 58 teses e dissertações apresentaram crescimento no período com ápice em 2010 e 2013, autoria e orientação prevalentemente feminina e nas regiões sudeste, centro-oeste e sul. Os 38 artigos também apresentaram crescimento numérico com ápice em 2014, distribuição de gênero mais equitativa e maior concentração em revistas publicadas na região sudeste. Os artigos foram analisados em relação ao seu tratamento de racismo, etnocentrismo e outras discriminações nas escolas e, em síntese, a análise da produção mostrou que o maior avanço nesse processo foi o de reconhecimento de manifestações e consequências do racismo, do etnocentrismo e de outras discriminações na vida de aluno/ as, e de seus professores, não só dos negros, mas também dos não-negros, bem como na organização e funcionamento de instituições educacionais.

Palavras-chave: Relações étnico-raciais. Racismo. Etnocentrismo. Discriminação. Revisão sistemática.
\end{abstract}

\footnotetext{
ABSTRACT

This article reviews 38 articles, 7 theses and 51 dissertations from the area of education published in Brazil between 2003 and 2014 that deal with the

* Universidade Federal de São Carlos. Centro de Educação e Ciências Humanas. E-mail: pbgs@terra.com.br. ORCID: https://orcid.org/0000-0001-8312-2262
} 
theme of education of ethnic-racial relations in schools. Most writings record results are experiences of education in educational institutions, as well as considerations, assessments, reflections, suggestions regarding ethnic-racial education. The 58 theses and dissertations presented growth in the period with apex in 2010 and 2013, authorship and advisers predominantly female and for am regions southeast, center-west and south. The 38 articles also presented numerical growth with apex in 2014, a more equitable gender distribution and a higher concentration in journals published in the southeast region. The articles were analyzed in relation to their treatment of racism, ethnocentrism and other discrimination in schools and, in summary, the analysis of the production showed that the greatest advance in this process was the recognition of manifestations and consequences of racism, ethnocentrism and other discrimination in the lives of students and their teachers, not only blacks, but also non-blacks, as well as in the organization and functioning of educational institutions.

Keywords: Ethnic and race relations. Racism. Ethnocentrism. Discrimination. Systematic review.

A pesquisa Educação e Relações Étnico-Raciais: o Estado da Arte objetivou mapear e sintetizar a produção acadêmica sobre educação e relações étnico-raciais entre 2003 e 2014, no Brasil, por meio da leitura de teses e dissertações realizadas nos programas de pós-graduação stricto sensu em Educação, bem como de artigos publicados em periódicos Qualis A e B na área da Educação, e de livros produzidos pelos Núcleos de Estudos Afro-Brasileiros (NEABs) e grupos correlatos.

O presente artigo abrange artigos, dissertações e teses que abordaram questões relativas à educação das relações étnico-raciais em instituições educacionais. Diga-se, de saída, que as instituições educacionais focalizadas nas pesquisas disponíveis foram, em sua significativa maioria, instituições regulares de ensino, notadamente de educação fundamental, anos iniciais, também de educação infantil e Educação de Jovens e Adultos (EJA).

Para realização da presente pesquisa, identificaram-se 38 artigos que, em sua maioria, registram resultados, experiências de educação em estabelecimentos de ensino, bem como considerações, avaliações, reflexões, sugestões no que diz respeito à educação étnico-racial. Também foram analisadas 7 teses e 51 dissertações, realizadas entre os anos 2004 e 2014. 


\section{As dissertações e teses}

Inicialmente, cabe mencionar que, nas 58 dissertações e teses examinadas, mulheres mostraram mais interesse do que homens para pesquisar questões relativas à educação das relações étnico-raciais em instituições de ensino. Exemplo está no fato de $88 \%$ das pesquisas de mestrado terem sido realizadas por estudantes mulheres, bem como orientadas por $85 \%$ de doutoras.

Algumas dessas pesquisas foram desenvolvidas por professoras, sobretudo em exercício na Educação Básica, incluindo EJA - Educação de Jovens e Adultos, bem como na Educação Infantil. A produção foi crescente, entre os anos de 2008 e 2014, registrou-se o maior número de produção que abordou problemáticas relativas à educação das relações étnico-raciais em instituições educacionais, destacando-se os anos de 2010 e 2013. É provável que a proximidade dos dez anos de promulgação da Lei 10.639/2003, completados em 2013, tenha despertado interesse no sentido de avaliar em que medida e como a sua implantação vinha ocorrendo.

\section{GRÁFICO 1 -ANO DE PUBLICAÇÃO DAS DISSERTAÇÕES E TESES}

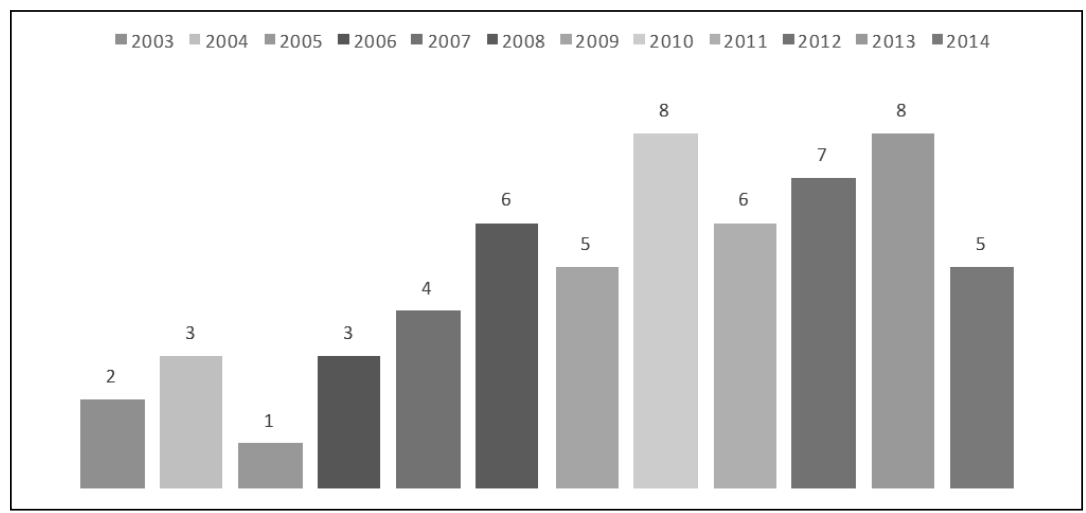

FONTE: Pesquisa Educação e Relações Étnico-Raciais: O Estado da Arte, 2017.

As instituições onde os trabalhos foram defendidos foram 25 no total, com bastante dispersão (Gráfico 2). A instituição onde se realizou o maior número de pesquisas relativas à educação das relações étnico-raciais em instituições escolares foi a Universidade Federal do Mato Grosso (UFMT), com 12 investigações, seguida da Universidade Federal de São Carlos (UFSCar) com 7 
e da Universidade de São Paulo (USP), Universidade Estadual de Campinas (UNICAMP) e Universidade do Estado da Bahia (UNEB) com 5.

GRÁFICO 2 - INSTITUIÇÕES DE PUBLICAÇÃO DAS TESES E DISSERTAÇÕES

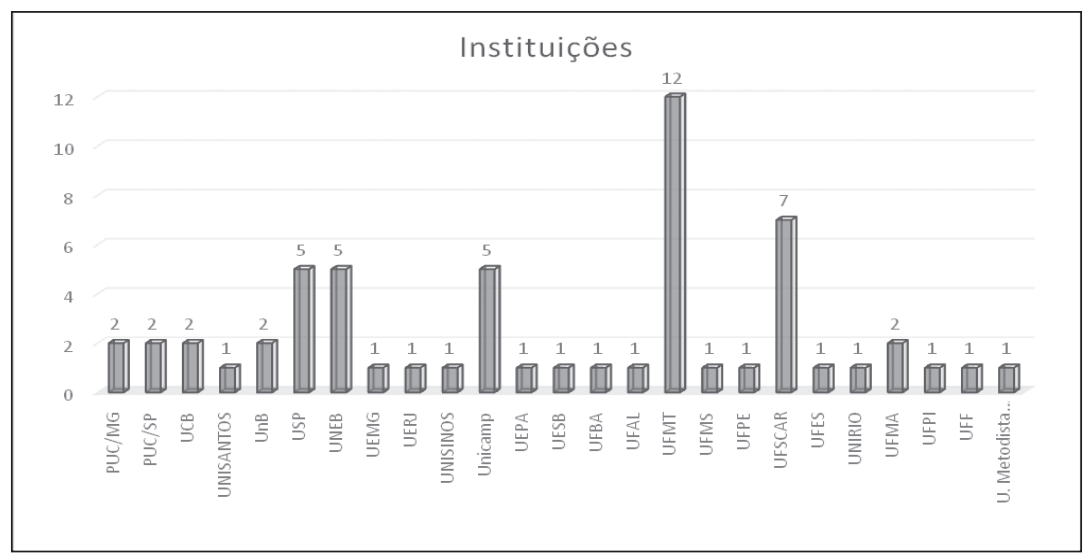

FONTE: Pesquisa Educação e Relações Étnico-Raciais: O Estado da Arte, 2017.

Analisando a produção em pauta, por região, verifica-se que $28,47 \%$ se localizou na região Sudeste, seguida da Centro-Oeste com 17,29\% e da Nordeste com $12,20 \%$. As regiões Norte e Sul participaram da produção com $1,2 \%$, cada uma. Observa-se um significativo número de trabalhos defendidos nas regiões Centro-Oeste pela UFMT, Universidade de Brasília (UNB) Universidade Federal do Mato Grosso do Sul (UFMS) e Universidade Católica de Brasília (UCB) e Nordeste UNEB, Universidade Federal de Alagoas (UFAL), Universidade Federal da Bahia (UFBA), Universidade Federal do Maranhão (UFMA), Universidade Federal de Pernambuco (UFPE), Universidade Federal do Piauí (UFPI), Universidade Estadual do Sudoeste da Bahia (UESB), para além da maior proporção na região Sudeste. Cabe lembrar que na região Sudeste se concentra o maior número de cursos de pós-graduação em educação; assim como mencionar a ênfase a pesquisas sobre educação das relações étnico-raciais na região Centro-Oeste, notadamente junto à UFMT. Salienta-se que a maioria significativa, ou seja, 42, dessas pesquisas não relataram nos textos o apoio de financiamento; que 7 receberam apoio da Coordenação de Aperfeiçoamento de Pessoal de Nível Superior (CAPES) e uma da Fundação FORD.

A seguir, são apontadas temáticas, problemáticas abordadas nessas pesquisas. Os interesses e curiosidades dos pesquisadores, cujas investigações foram analisadas, dizem respeito a: 
- perpetuação do racismo em ambientes escolares; preconceito racial (ALGARVE, 2006; SOUZA, 2006; CONSTANTINO, 2007; DEMARSO, 2007; KABEYA, 2007; FOSTER, 2009; COSTA, 2010; MACHADO, 2010; BOUCAS, 2011; GOMES, 2012; BONILHA, 2014);

- relações étnico-raciais entre alunos e professores, alunos-alunos (RAMOS, 2003; CHAGAS NETO, 2004; ALEXANDRE, 2006; PAULINO, 2008; ZANDONA, 2008; MOURA, 2009; OLIVEIRA, 2009; CALADO, 2010; CRUZ, 2010; SANTOS, 2010; MACHADO, 2011; ABREU, 2012; NEVES, 2012; RODRIGUES, 2013; BATISTA, 2014; CONCEIÇÃO, 2014; CRUZ, 2014; SANTIAGO, 2014);

- desempenho escolar e trajetórias escolares (SANTANA, 2005; JESUS, 2006; SILVEIRA, 2008; SOUZA, 2008; MONTEIRO, 2013; TRINIDAD, 2013);

- preconceito racial e identidade (SILVA, 2003; SILVA, 2004; FIRMO, 2006; RODRIGUES, 2007; MACÊDO, 2011; SILVA, 2011; SANTOS, 2012; TELES, 2012; ALEXANDRE, 2013; SANTOS, 2013);

- implantação das Diretrizes Curriculares Nacionais para a educação das Relações Étnico-Raciais e para o Ensino de história e Cultura Afro-Brasileira e Africana ${ }^{1}$ : gestão escolar e conselhos escolares (ZANDONA, 2008; TEIXEIRA, 2010);

- pedagogia antirracista (GONÇALVES, 2010; ALVES, 2013);

- significado de ser branco (ALVES, 2008);

- propostas para Estudos Afro-Brasileiros (ALMEIDA, 2009)

- instituição de Ensino Superior para inclusão da População Negra - entre objetivos declarados e objetivos atingidos (SOUZA, 2013).

Cabe, ainda, apontar outros interesses e preocupações manifestados nas teses e dissertações examinadas. Dizem, eles, entre outros, respeito a: - tradições afro-brasileiras na escola; - compreensão do que seja a diversidade humana; construção de pertencimento étnico-racial; - compreensões de expressões de negritude; - identidade, cultura e classe social; - silêncios diante de racismo e discriminações. Nota-se preocupação em realizar pesquisas com crianças e professores dos anos iniciais a respeito de experiências de racismo, autodeclaração a respeito de raça/cor, persistência de representação estereotipada de negros e de cultura afro em materiais didáticos, comparação de desempenho escolar entre crianças negras e não negras.

1 O Parecer CNE/CP 3/2004 e a respectiva Resolução CNE/CP 2/2004 estabelecem as Diretrizes Curriculares Nacionais para a educação das Relações Étnico-Raciais e para o Ensino de história e Cultura Afro-Brasileira e Africana. 
Os suportes teórico-metodológicos ancoram-se em diálogos com produções da área da Educação, bem como da Antropologia, Sociologia da Infância, Estudos Culturais. Os autores mais citados para construção das referências teórico-metodológicas são: - entre os nacionais: K. Munanga, Nilma L. Gomes e Eliane Cavalleiro; - entre os demais: Pierre Bordieu; Edgard Morin, Michel Foucalt, e Hall Stuart. Sem dúvidas, tratam-se de pesquisadores-chave para conhecimento e discussões da problemática das relações étnico-raciais, entretanto, chama a atenção, a falta de busca de referências, entre já não rara produção brasileira sobre ou relacionada a relações étnico-raciais e educação, bem como o pouco conhecimento ou ausência de autores latino-americanos e africanos. Os encaminhamentos e procedimentos metodológicos utilizados foram de caráter qualitativo, destacando-se observações inspiradas em estudos etnográficos, também entrevistas, depoimentos e questionários, além de diário de campo, atividades pedagógicas, desenhos, jogos e brincadeiras.

\section{Os artigos}

Foram analisados 38 artigos, com foco em questões relacionadas a racismo, etnocentrismo e outras discriminações, tendo como referência central, mas não exclusiva, o Parecer CNE/CP 3/2004 e a Resolução CNE/CP 1/2004, que tratam da educação das relações étnico-raciais e do ensino de história e cultura afro-brasileira e africana, nos sistemas e estabelecimentos de ensino brasileiros.

Os artigos contaram com 59 autoras/es, de 24 diferentes instituições e 24 programas distintos de pós-graduação. Diferentemente das teses e dissertações que apresentaram hegemonia feminina na autoria e na orientação, nos artigos a distribuição de gênero da autoria foi equitativa, com $39 \%$ de autoria feminina, $39 \%$ masculina e $22 \%$ mista.

As revistas nos quais os artigos foram publicados foram na maioria da região Sudeste, com índice pequeno na região Centro-Oeste e na região Sul, ainda menor na região Nordeste e nenhum na região Norte. Na distribuição de região das instituições dos autores, $47 \%$ foram da região Sudeste, $13 \%$ da região Sul, $11 \%$ da região Norte, $10 \%$ da Centro-Oeste e $8 \%$ da Nordeste (Gráfico 3). 
GRÁFICO 3 - REGIÃO DE VÍNCULO INSTITUCIONAL DOS/AS AUTORES/AS

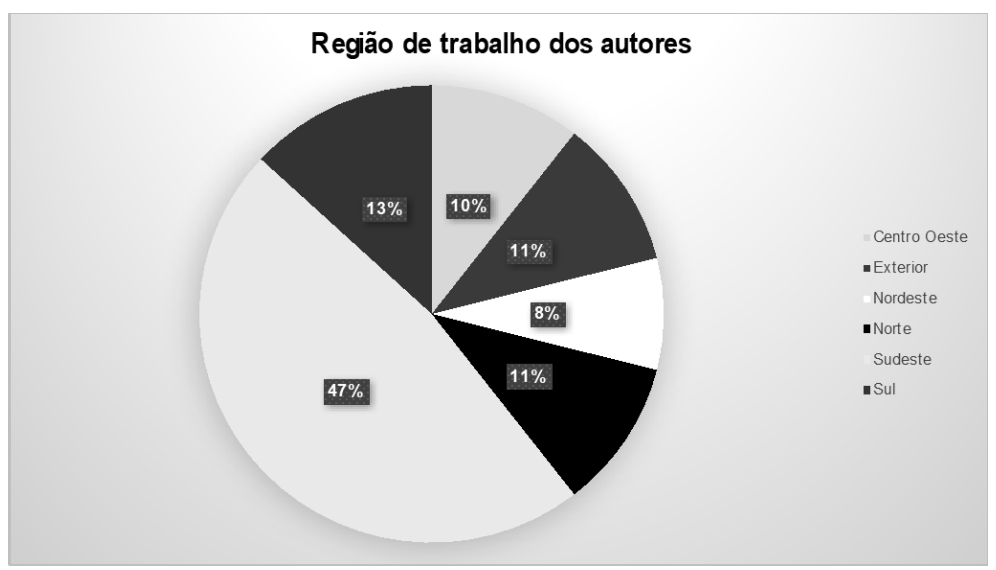

FONTE: Pesquisa Educação e Relações Étnico-Raciais: O Estado da Arte, 2017.

De forma similar às teses e dissertações, os casos de indicação de financiamento das pesquisas foram esporádicos, com 3 casos relatando financiamento do Conselho Nacional de Desenvolvimento Científico e Tecnológico (CNPq), 1 da CAPES e 1 da Fundação Ford. A distribuição ao longo dos anos apresentou crescimento constante, com picos em 2014 e 2011e baixa em 2012 e 2013 (Gráfico 4).

GRÁFICO 4 - ANO DE PUBLICAÇÃO DOS ARTIGOS

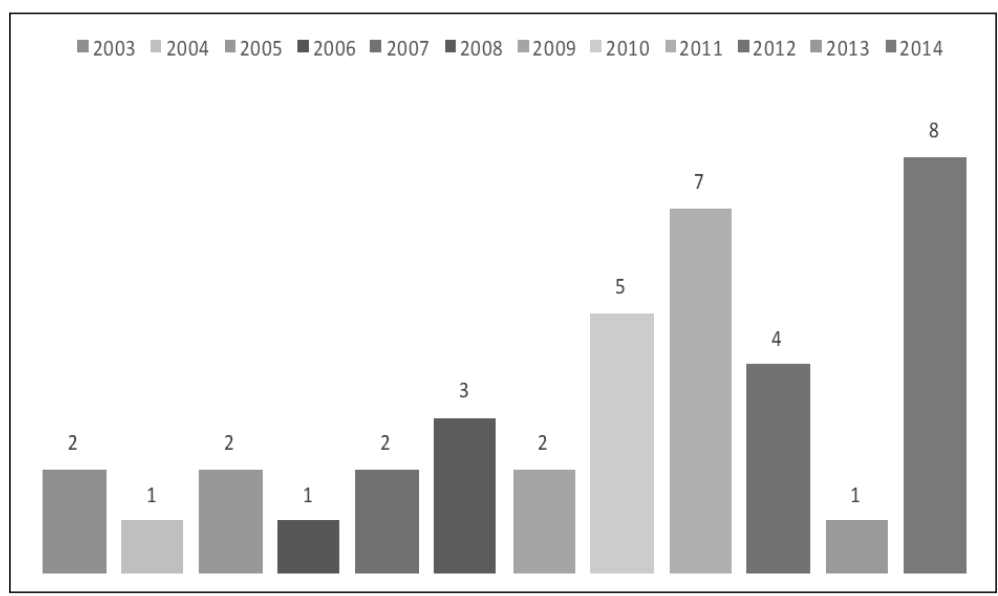

FONTE: Pesquisa Educação e Relações Étnico-Raciais: O Estado da Arte, 2017. 


\section{O conteúdo dos artigos}

Foram analisados os 38 artigos, com foco nas seguintes questões: Racismo, Etnocentrismo e Outras Discriminações, tendo em vista, a partir do Parecer CNE/CP 3/2004 e da Resolução CNE/CP 1/2004, que tratam da educação das relações étnico-raciais e do ensino de história e cultura afro-brasileira e africana.

Um primeiro grupo de estudos trata do racismo nas instituições escolares. Alguns artigos abordam o que chamam de racismo implícito e de racismo explícito, conduzindo assim ao entendimento do que seria a teoria do embranquecimento. (PICCOLO, 2010; GUIMARÃES, 2014; PINHO e SANTOS, 2014; SCHNEIDER e BIRANOSKI, 2014). Outros tratam de questões relativas ao racismo institucional, que prejudica os negros quando da implantação de políticas públicas dirigidas a todos os cidadãos (GUIMARÃES, 2003; SOARES e ALVES, 2003; CARVALHO, 2004; 2005; SILVA e TEIXEIRA, 2009; ABRAMOWICZ e OLIVEIRA, 2010; SOUZA, RIBEIRO e CARVALHAES, 2010; ARTILES, KOZOLESKI e GONZALES, 2011; SOUZA, 2011; GLASS, 2012; AQUINO et alii, 2013; ROSEMBERG, 2014). No plano institucional, Rosemberg (2014) considera que as desigualdades entre brancos e negros, no acesso a bens sociais, se devem ao racismo da sociedade brasileira. Racismo que configura a adoção da ideologia de superioridade natural dos brancos sobre os demais, notadamente sobre os negros. O racismo se manifesta, de forma aberta ou velada, por meio de expressões que qualificam os negros como inferiores aos brancos. Mas manifesta-se principalmente nas políticas educacionais universalistas, "que, no Brasil, de democráticas, pouco têm" (ROSEMBERG, 2011, p. 757), em virtude do racismo institucional, que privilegia a brancos.

Diversos estudos observaram nas instituições escolares situações que geram experiências de racismo, bem como expressões utilizadas para depreciar pessoas negras, qualificando-as como inferiores, violentas, indolentes, perigosas (PICCOLO, 2010; ABRAHÃO e SOARES, 2011; GUIMARÃES, 2014; PINHO e SANTOS, 2014; SCHNEIDER e BIRANOSKI, 2014). A associação entre ser negro e ser pobre é frequentemente confirmada nos diversos artigos analisados. Há artigos que apontam o uso de estereótipos raciais, por meio de apelidos e ofensas, que depreciam e desqualificam os povos negros e indígenas, nas relações entre estudantes de diferentes níveis de escolarização, desde a Educação Infantil (SILVA, 2008; SILVA e TEIXEIRA, 2009; FERRARI, 2010; PICCOLO, 2010; SILVA e PALUDO, 2011; SILVA e MORAIS, 2012; CRUZ, 2014; LEMOS, CRUZ e SOUZA, 2014; SILVA, 2014).

Outra constatação importante é de que a ação mais comumente utilizada para combater o racismo nas escolas é o "silenciamento", por parte dos pro- 
fessores, equipe pedagógica e direção das escolas (CARVALHO, 2005; ROSEMBERG E ROCHA, 2007; SILVA E PALUDO, 2011; SILVA, 2008; SILVA, 2012; COSTA e SANTOS, 2014). O "silenciamento" é uma das ações, atitudes, estratégias adotadas pela escola brasileira para o enfrentamento do racismo. Dessa forma, de um lado professores não costumam intervir diante de conflitos que agridem crianças negras, em virtude de sua raça/cor, de outro, recomendam aos alunos negros, quando hostilizados por sua cor/raça, que ignorem, finjam que a agressão não é dirigida a eles. Os referidos artigos ressaltam que há pouca ou nenhuma intervenção das professoras em relação às situações de rejeição e discriminação vividas pelas crianças. A pouca ou a ausência de intervenção causa sofrimento junto às crianças negras, intensificando a baixa autoestima, além, de promover segregação e pouca convivência entre crianças negras e não negras. (ROSEMBERG E ROCHA, 2007; SILVA E PALUDO, 2011; SILVA, 2008; SILVA, 2012; COSTA e SANTOS, 2014).

Em razão de racismo no funcionamento da escola, do currículo até os livros didáticos não contemplam a diversidade que a escola atende, excluem, notadamente os negros e indígenas. (SOARES e ALVES, 2003; ABRAMOWICZ, 2006; PICCOLO, 2010). As universidades têm currículo e produção de conhecimento fundadas no modelo eurociêntrico (AQUINO et alii, 2013). Além disso, os negros são prejudicados em razão do fato de os professores associarem aluno negro a problemas de desempenho. Destacam, diferentes artigos, a dupla discriminação que sofrem as alunas negras, por serem mulheres e negras, bem como, a ausência de suporte, nas instituições educacionais, para gerenciar conflitos dessa natureza (SOARES e ALVES, 2003; SILVA, 2008; FERRARI, 2010; ROACH, 2011; CRUZ, 2014).

Um artigo revelou tensões entre as crianças, quando crianças negras se propõem a assumir posições que usualmente são destinadas na sociedade para pessoas brancas, por exemplo, - professor/a, médico/a, dona da casa, entre outras (PICCOLO, 2010). Silva (2012) trata da situação de professor, homem negro, na educação infantil, ser duplamente discriminado, sofrendo racismo e sexismo. Outro artigo argumenta que a medicalização da educação, argumentam alguns autores, fez com que diferenças fossem transformadas em patologias, para justificar os racismos e consequente desigualdades (LEMOS, CRUZ e SOUZA, 2014).

Alguns artigos destacam o conflito que os negros enfrentam nas situações cotidianas, o que faz com que muitos adotem como comportamento passividade, negação (SILVA, 2008 SILVA e PALUDO, 2011).

Ao tratar do "fracasso escolar", argumentam Soares e Alves (2003) que há um recorte racial e social, pois quando as condições sociais são as mesmas, ainda assim, os negros são os que apresentam um índice maior de fracasso escolar. 
Souza, Ribeiro e Carvalhaes (2010) destacam que a discriminação racial tem papel importante mesmo em um regime de baixa mobilidade. Desse modo, a discriminação racial, concluem, os autores, seria um impedimento que garantiria a estabilidade das desigualdades. Resultados do estudo sugerem que o efeito mais forte da cor e da origem social se evidencia nos processos de aquisição de escolaridade e não na trajetória dentro do mercado de trabalho propriamente dito. Ferraro e Oliveira (2009) apontam: há diferenças no recrutamento para as redes escolares que operam na direção da difusão da crença que crianças negras não sejam educáveis e as grandes diferenças regionais são outro ponto que sustenta desigualdades educacionais para negros e pobres. Carvalho $(2004 ; 2005)$ percebeu que a maioria de meninos negros tendia a obter conceitos negativos e serem indicados para atividades de recuperação; identificou que normalmente professoras tendiam a perceber como negras crianças com problemas de aprendizagem e mostram tendência em avaliar de forma negativa o desempenho de crianças negras. Além disso analisou a hipótese de que a classificação racial pelas professoras era influenciada pelo desempenho dos/as alunos/as (CARVALHO, 2005, p. 91).

Diversos artigos discutem aspectos conceituais e dois artigos focam a discussão nos conceitos de raça e racismo (GUIMARÃES, 2003; GLASS, 2012), ponderam que, em seu início, as ciências como a Biologia e a Antropologia criaram a ideia de raças humanas superiores e inferiores, o que ajudou a criar teorias e comportamentos racistas que persistem. A classificação do que seriam as diferentes raças, as associava tanto a características físicas, como a distintos valores morais, dotes psíquicos e intelectuais. Assim, segundo os autores, se hierarquizaram as culturas, as sociedades e as populações humanas, criando fundamentos para racismos.

Há que ressaltar que diversos desses artigos mencionam, tratam de possibilidades para a educação crítica e antirracista, com vistas à construção de uma sociedade mais humanitária e justa (VALENTE, 2005; FRANCISCO JÚNIOR, 2011; ARTILES, KOZOLESKI e GONZALES, 2011; SILVA, 2011; GLASS, 2012).

Numa segunda categoria de agrupamento dos artigos, em relação ao etnocentrismo, os artigos afirmam que a escola é um espaço em que os valores eurocêntricos são difundidos e privilegiados, em detrimentos de outras culturas, notadamente, as culturas afro-brasileira e indígena, relegadas a segundo plano, quando não omitidas. Um deles aponta que o material didático está repleto de conteúdos depreciativos e preconceituosos em relação aos negros e povos indígenas, o que pode contribuir para o fracasso escolar dos alunos pertencentes a esses grupos (SILVA e MORAES, 2015). Outro destaca que, nas escolas de fronteira, a comunicação entre os alunos é marcada por hostilidades, que mostra 
a necessidade e importância de educação que focalize as relações étnico-raciais (PEREIRA, 2011). Almeida (2009) analisa formas de estruturação do racismo contra não europeus em exposições e feiras universais.

Alguns artigos argumentam que o ambiente escolar é um local de práticas educacionais, em que valores eurocêntricos prevalecem, por isso abriga preconceitos e atitudes discriminatórias, veiculados cotidianamente, inclusive por materiais didáticos, tanto impressos, audiovisuais, como outros elaborados por professores, alunos (PICCOLO, 2010; PINHO e SANTOS, 2014). Um artigo aponta que o acolhimento das diferenças culturais e sociais, em escolas, passa a ocorrer em virtude da normatização por meio de políticas públicas educacionais, que deveriam incidir sobre a prática escolar do dia a dia (FERRARO e OLIVEIRA, 2009). Estudando escolas de fronteiras, Pereira (2012) observou seus estudantes muitas vezes eram designados por apelidos, em geral pejorativos, relativos aos pertencimentos étnicos e culturais, bem como às diferenças relativas à alimentação, vestuário e trabalho. Destaca que os alunos ao serem discriminados, nem sempre reconhecem as atitudes agressivas como discriminatórias, considerando-as brincadeiras de mau gosto. Assim, na escola de fronteira, a comunicação entre os alunos é repleta de hostilidade, o que sinaliza a diferença étnico-cultural como característica negativa. Em artigo sobre negritudes e aprendizagem cotidiana, os autores abordam a riqueza cultural africana, destacando a mitologia, a cosmologia, a botânica, etc., e questionam por que educadores que, segundo os autores, vivem, em grande parte, em contexto cultural popular de maioria africana, desconhecem ou desconsideram esses saberes, o que implica em não incluí-los em suas práticas pedagógicas (FERNANDES, NAZARETH e REIS, 2008). O conjunto dos artigos indica que a prática escolar, baseada na uniformidade cultural e social, transforma diferenças em desigualdades, com marcante desvantagem para negros, indígenas, empobrecidos, mulheres, deficientes, Lésbicas, Gays, Bissexuais, Travestis, Transexuais e Transgêneros (LGBT). Também se considera como manifestação informada por etnocentrismo, a intolerância religiosa, notadamente contra religiosidades de raiz africana como, entre outros, o candomblé.

Uma terceira categoria que observamos foram artigos que tratam de outras formas de discriminação além do racismo e etnocentrismo. Diversos desses artigos tratam da classe social e as discriminações a ela associadas, muitos deles cruzando as discriminações de classe com raça e/ou gênero (GUIMARÃES, 2003; SOARES e ALVES, 2003; FERRARO e OLIVEIRA, 2009; YANNOULAS, ASSIS e FERREIRA, 2012). Os artigos de Guimarães (2014) e de Lemos, Cruz e Souza (2014) tratam do fracasso escolar em escolas situadas na periferia. Os autores sublinham que os próprios alunos eliminados pela escola, bem como suas famílias, confirmam a ideia de que o sucesso escolar seria decorrente de 
trabalho e de "dons", e que o fracasso não está relacionado à condição social de pobreza. Destacam, os autores, que o êxito escolar e a ascensão social adquirida por membros de famílias pobres reforçam a aparência de legitimidade da seleção escolar.

Ferraro e Oliveira (2009) desenvolvem o argumento de que pensar sobre a condição social implica pensar sobre diferença. Em conformidade com esses autores, a diferença aparece sempre como uma espécie de parâmetro de determinação da condição, explicitando a condição social, o comportamento, o modo de produção de vida, entre outros, que fogem ao padrão etnocêntrico convencional. O artigo de Boneti (2010) apresenta a escola como espaço sociocultural pleno de contradições, abrigando, relações entre crianças que tanto podem reforçar como questionar as práticas discriminatórias vigentes na escola. $\mathrm{O}$ autor expõe que há um processo dinâmico na escola, de possibilidades e necessidades, além de destacar que as discriminações relacionadas à raça e gênero são frequentes entre as crianças e constituem um rol maior de comportamentos discriminatórios de características pessoais, como peso, beleza, agilidade física e mental, entre outras (BONETI, 2010).

Em síntese, a análise dessa produção acadêmico-científica sobre $e d u$ cação das relações étnico-raciais em instituições educacionais, centrada em questões relativas a manifestações de racismo, etnocentrismo e outras discriminações, mostrou que o maior avanço nesse processo foi o de reconhecimento de manifestações e consequências do racismo, do etnocentrismo e de outras discriminações na vida de aluno/as, e de seus professores, não só dos negros, mas também dos não negros, bem como na organização e funcionamento de instituições educacionais.

Os artigos analisados mostram que situações criadas por atitudes, expressões de racismo, etnocentrismo, bem como de outras discriminações são recorrentes em escolas e universidades, e que, muitas vezes, experiências dessa natureza já são vividas fora do ambiente escolar, inclusive no seio de algumas famílias. Destacam, não poucos estudos, que, com frequência, a única medida tomada, pela escola, para auxiliar os alunos que sofrem racismo é a de incentivá-los a fingir que não perceberam a agressão. Cultiva-se, assim, uma cultura de silenciamento, que incentiva a continuidade de discriminações e naturaliza o racismo. Em mais de um artigo, se faz referência a vocabulário hostil, utilizado para os xingamentos, ofensas e humilhações de caráter racista, sexista, xenófobo, que desqualificam pessoas e grupos étnico-raciais, bem como a necessidade de desconstruí-lo.

Há artigos em que se insiste na necessidade de investimentos no sentido de combater tais comportamentos e manifestações, desde a educação infantil, em atividades de que participem as famílias e comunidades de que as crianças 
fazem parte. Indicam, eles, também preocupação com o preparo dos professores, direção, equipe pedagógica e funcionários das instituições que deve ser permanente, no sentido de garantir que as situações de conflito entre alunos e/ ou alunos e professores sejam adequadamente abordadas, por profissionais qualificados, bem como em permanente processo de qualificação e aprimoramento para combater racismos e discriminações.

Alguns dos artigos insistem que cursos de graduação, licenciaturas não têm preparado adequadamente, ou simplesmente ignoram a problemática das relações étnico-raciais, como objeto importante de estudo e de práticas pedagógicas. Sugere-se, por exemplo, que se examinem nesses cursos, bem como em outros de formação continuada, para que futuros professores e professores já em exercício aprendam a assumir postura de combate ao racismo, a etnocentrismos e outras discriminações, de maneira efetiva, por meio de instrumentos pedagógicos.

\section{Considerações finais}

Muita complexidade envolve as relações étnico-raciais na sociedade brasileira e, é claro, não poderia ser diferente, nos ambientes escolares, universitários. Sem dúvida alguma, as políticas públicas estabelecidas pelas Leis 10639/2003 e 11645/2008 criam condições para que discriminações e racismos possam ser superados em escolas e universidades. A primeira foi regulamentada, pelo Conselho Nacional de Educação, respectivamente, por meio do Parecer CNE/ CP 3/2004, bem como pela Resolução CNE/CP1/2004 que tratam das Diretrizes Curriculares Nacionais para Educação das Relações Étnico-Raciais e para o Ensino e cultura Afro-Brasileira e Africana. A segunda o foi, por meio do Parecer CNE/CEB 14/2015 que trata de Diretrizes Operacionais para Implementação da História e das Culturas dos Povos Indígenas na Educação Básica, em decorrência da Lei 11645/2008.

O problema não está, portanto, na falta de políticas públicas, tampouco de orientações para implementá-las (ver SILVA e ARAÚJO, 2011), mas em projeto de sociedade que ainda se faz dominante, projeto esse que tenta eliminar as diferenças étnico-raciais, folclorizar as marcas culturais, sabedoria, conhecimentos, tecnologias que não de raízes europeias.

A Prof ${ }^{a}$ Dr $^{a}$ Rita Gomes do Nascimento, do Povo Potyguara, ao relatar o Parecer CNE/CEB 14/2015, destaca: 
A inclusão da temática da história e cultura indígenas nos currículos objetiva promover a formação de cidadãos atuantes e conscientes do caráter pluriétnico da sociedade brasileira, contribuindo para o fortalecimento das relações interétnicas positivas entre os diferentes grupos étnicos e raciais e a convivência democrática, marcada por conhecimento mútuo, aceitação de diferenças e diálogo entre culturas. (BRASIL, 2015).

De fato, é difícil contrapor-se a essa proposta, entretanto para fazê-lo, precisa-se enfrentar mecânicas de desigualdades construídas pelos colonizadores europeus e por seus seguidores, ao longo dos tempos, desde o século XVI até o atual século XXI. Tem-se que fazer frente a tentativas de eliminar as diferenças, transformando-as em exotismo, ou deficiências; é indispensável se contrapor a processos de assimilação a pensamentos, comportamentos, projetos unicamente de raiz europeia. O diálogo entre culturas é o grande desafio da educação das relações étnico-raciais. Como estabelecer diálogo entre distintas visões de mundo? Como negociar mudanças? Como estabelecer metas e atingi-las, sem imposições? Que elos queremos criar? Que elos há que romper? Em se tratando de estabelecimentos de ensino, inclusive universitários, que pedagogias somos constrangidos a criar? Como fazer face ao confronto entre branquitude e negritude? Entender que não se trata de uma disputa, uma vez que negritude não é um status, uma posição, mas um movimento de afirmação e reconhecimento das raízes africanas, como bem salienta Steve Biko:

- Ser negro não é uma questão de pigmentação - ser negro é o reflexo de uma atitude mental;

- Não basta descrever-se como negro, para dar início à emancipação; é preciso comprometer-se consigo mesmo no sentido de lutar contra todas as forças que tentam usar sua negritude como uma estampa que marca como um ser humano subserviente. (BIKO, 1995, p. 537).

Diante das indagações e desafios apontados, é de se comportar, conforme tem feito Jansen (2009), na sua experiência enquanto professor e reitor de universidade na África do Sul. Tem enfrentado, ele, com paciência e estudo de realidades, as desconfianças e tensões decorrentes do esforço para negociar mudanças.

Como se vê, educar, reeducar relações étnico-raciais implica aprender a negociar mudanças, nas relações entre pessoas, na organização da sociedade. 
É encarando esses desafios, que ao concluir a pesquisa sobre Educação das Relações Étnico-Raciais em Instituições Educacionais, tenta-se apontar pelo menos alguns dos enfrentamentos a fazer face. E começa-se perguntando: Podem

\section{pesquisas contribuir para educação das relações étnico-raciais?}

Pesquisas, como qualquer ação humana, se inscrevem em projetos de sociedade, de vida, assumidos, valorizados por quem se dedica a investigar. Investigações que se ocupam de políticas para educação, de projetos pedagógicos, de processos educativos, enraizados em referências teóricas historicamente situadas, tanto buscam compreender, como configurar, influenciar processos de estudar que resultem em aprendizagens e em consequentes ensinos.

Isto posto, cabe, a seguir, tecer algumas considerações provocadas pelo estudo dos referidos artigos, dissertações e teses. Uma questão que se põe de saída vai no sentido de entender por que pesquisadores, no presente caso, na sua maioria pesquisadoras, selecionam um tema, uma hipótese, questão de pesquisa e, embora realizando trabalho dentro das mais restritas regras científicas, não tomam conhecimento ou desprezam referências da realidade e também teóricas anteriormente produzidas?

Siegel (2006), Banks (1998), entre outros, ajudam a responder à questão posta. Sublinham, essa autora e esse autor, que a formulação de questões, hipóteses de pesquisa é orientada por condições culturais, raciais, de gênero, entre outras que situam, circunscrevem o/a pesquisador/a. Curiosidades e interesses pessoais, disponibilidades de financiamento, incentivos para produção de conhecimentos sobre determinadas questões orientam escolhas por temas para pesquisar, por orientações teórico-metodológicas, bem como por meios para divulgar os resultados, assim como para quem divulgar. Assim, sendo não é de se estranhar que haja pesquisadores que desenvolvem estudos, já no fim da década dos anos 2000, sobre, por exemplo, percepções de racismo entre crianças negras e não negras, entre estudantes negros e brancos, entretanto, nem mesmo mencionem a Lei 10.639/2003.

Sem dúvidas, é difícil entender essa omissão como desconhecimento, em virtude da ampla divulgação da Lei 10.639/2003, do Parecer CNE/CP 3/2004 e da Resolução CNE/CP 1/2004, desde 2004, pelo Ministério da Educação, dos inúmeros cursos de formação de professores promovidos pelo MEC, por secretarias de educação tanto estaduais como municipais. É difícil não interpretar essa omissão como sinal de um projeto de sociedade contrário à igualdade racial.

Urgências diante de problemas provocados por desigualdades, metas para promover emancipação de grupos sociais, implantação e avaliação de políticas públicas, defesa de direitos, mobilização de grupos sociais, combate a preconceitos e intolerâncias, tensões em relações sociais, educação de relações étnico-sociais, autonomia e empoderamento de movimentos e de ações sociais 
são motivos, entre outros, que levaram os pesquisadores, cujas investigações examinamos, a realizar suas dissertações ou teses. E o fizeram em perspectivas e com propósitos enraizados em projetos de sociedade que defendem.

Episódios de desrespeito, até mesmo de violência, agressões, em diferentes sociedades, se repetem cotidianamente, mundo a fora, tomando um caráter de "normalidade". Engajamento político é confundido com intolerância, direitos são interpretados como vantagens, pertencimento étnico-racial como superioridade ou desprestígio, bens públicos são geridos como se fossem privados. Em nome de direitos humanos, com diferentes objetivos, além do de obter o título de mestre ou de doutor, como no caso das pesquisas aqui examinadas, investiga-se. O que motiva o dedicar-se a pesquisar sobre isso ou aquilo, que interesses e metas incentivam, pesquisadores? Essas são questões que nos interpelam e cujas respostas ainda há que buscar.

Se o pesquisador mantém raciocínios, conhecimentos, relações pessoais excludentes, se esconde, sob discursos de inclusão, estratégias para converter aos interesses das autodenominadas elites, por meio da educação, empobrecidos, negros, indígenas, ciganos, transexuais, imigrantes recentes, entre outros marginalizados pela sociedade, seu trabalho até poderá ter relevância acadêmica, mas não o terá social (SILVA, 2005). Note-se que critério para avaliar relevância social vai no sentido de superação de desigualdades, racismos, discriminações negativas. Assim a ideia de um universalismo que seria capaz de unificar todas as diferenças culturais e sociais, que busca ajustar pensamentos, comportamentos, escolhas a um padrão que desconsidera, deprecia realidades, especificidades, experiências que dão significados a modos peculiares de ser e viver (ver, entre outros, TAPERNOUX, 1997; SILVA, 2001), não é cabível numa sociedade multicultural como a brasileira.

Pesquisas revelam a respeito da postura ética, teórica e política de quem realiza a pesquisa, de sua formação para pesquisar. Assim, os relatórios mostram pesquisador que se quer neutro, por isso não contextualiza o momento histórico-político em que se situam as questões que se propõem a investigar. Há também o pesquisador militante, defensor crítico ou não, ou combatente de políticas de ações afirmativas; esse mal e mal menciona a Lei 10.639/2003.

Entre as exigências científicas e compromisso social; entre discurso politicamente correto e convicções próprias; entre ser/parecer aliado nas lutas contra o racismo, discriminações, constroem, estudantes e seus professores, orientadores de teses e dissertações, a formação de pesquisadores.

As pesquisas examinadas, todas elas, partiram de uma boa ideia, de uma forte intuição, mas nem sempre, embora seriamente conduzidas, foram convenientemente apresentadas e divulgadas. Sem esquecer as pressões sobretudo de prazos, não é possível aceitar que o relatório final, disponibilizado para outros 
pesquisadores, contenham erros (alguns graves) ou informalidade de linguagem. Isso prejudica na divulgação da pesquisa e no emprego de seus resultados a quem interessar possa.

Linguagem, reveladora de firme postura política está presente em algumas pesquisas. Linguagem militante, no que diz respeito ao combate ao racismo, ao sexismo, entretanto desconhece e/ou discorda de políticas públicas como ações afirmativas. Linguagem "cientificamente" correta, com denúncias contra desigualdades, baseadas na experiência vivida ou observada de pesquisadores, entretanto ignora questões relativas a outras desigualdades, de que talvez não seja vítima.

As dissertações e teses analisadas, conforme já se mostrou anteriormente, abordaram, trataram, investigaram problemáticas, questões relacionadas a: culturas silenciadas ou "simplificadas" no currículo escolar; - representações de raça - negros, brancos; - representações de gênero e de branquitude, negritude; - experiências de racismo, autodeclaração a respeito de raça/cor, em anos iniciais de escolarização; - preconceitos em livros didáticos: persistência de representação estereotipada de negros; - desempenho escolar: comparação entre negros e brancos; - escola reprodutora, fomentadora de valores.

Quanto aos pesquisadores, sabe-se que são mestres ou doutores, com formação recente ou não, alguns, sobretudos professoras atuam no nível de ensino em que situam suas pesquisas. $\mathrm{O}$ fazem em busca de melhor compreender o que observam, vivem no dia a dia, bem como de melhor interferir. Há casos em que são militantes de alguma causa social, quase sempre movimento Negro, e buscam respostas para os desafios que enfrentam ou buscam respostas que elucidem se suas denúncias fazem sentido. Outros/as investigam com a expectativa de ajudar a superar percalços da implementação de políticas que visam superar desigualdades e por isso atingiriam modelo de sociedade dominante a séculos. Há quem se proponha a verificar o alcance dos cursos ERER, por exemplo, influência de cursos no desempenho político-pedagógico e identidade própria de professores.

O presente artigo se construiu em busca de respostas, encaminhamentos no que diz respeito de um lado a desafios, meios, esforços, para proceder educação das relações étnico-raciais, de outro, para identificar resultados desses esforços e, de outro ainda para conhecer a implantação das determinações da Resolução CNE/CP 1/2004 e do respectivo Parecer CNE/CP 3/2004.

Ao concluir provisoriamente. Toda conclusão humana, felizmente, é provisória, convém perguntar, sem ainda trazer respostas: Que perguntas, questões ainda nos atormentam? Que desafios ainda temos de enfrentar para educação das relações étnico-raciais? Para combater o racismo? Para produzir conhecimentos do interesse dos negros? Não só deles, mas de toda a população brasileira, na sua diversidade? 


\section{REFERÊNCIAS}

BANKS, Ja. A. The lives and values of researchers: implications for educating citizens in a multicultural society. Educational Researcher, v. 27, n. 7, p. 4-17, march 1998.

BIKO, S. The definition of Black Consciousness. In: COETZEE, P. H.; VAN DEN BERG, M. E. S. An Introduction to African Philosophy. Pretoria, University of South Africa, 1995. p. 536-554.

JANSEN, D. J. Knowledge in the Blood; confronting race and the apartheid past. Stanford, CA, Stanford University Press, 2009. 16-23.

SIEGEL, H. Epistemological Diversity and Education Research: Much Ado about nothing Much? Educational Researcher, Washington, American Educational Research Association, v. 35, n. 2, p. 3-12, March 2006.

SILVA, P. V. B.; ARAUJO, D. C. Educação em Direitos Humanos e Promoção da Igualdade Racial. Linhas Críticas (UnB), v. 17, p. 483-505, 2011.

SILVA, P. B. G. E. Pesquisa e luta por reconhecimento e cidadania. In: ABRAMOWICZ, A.; SILVERIO, V. R. Afirmando diferenças: montando o quebra-cabeça da diversidade na escola. Campinas: Papirus, 2005. p. 27-54.

SILVA, P. B. G. E. Pode a educação prevenir contra o racismo e a intolerância. In: SABOIA, G. V. Anais dos Seminários Regionais Preparatórios para a Conferência Mundial contra o Racismo, Discriminação Racial, Xenofobia e Intolerância Correlata. Brasília: Ministério da Justiças, Secretaria de Estado de Direitos Humanos, 2001. p. 103-122.

TAPERNOUX, P. Les Enseignants face au racisme. Paris: Anthropos, 1997.

\section{Artigos analisados}

ABRAHÃO, B. O. de L.; SOARES, A. J. G. O corpo negro e os preconceitos impregnados na cultura: uma análise dos estereótipos raciais presentes na sociedade brasileira a partir do futebol. Movimento, Porto Alegre, v. 17, n. 4, p. 265-280, out./dez de 2011. Disponível em: <http://www.seer.ufrgs.br/Movimento/article/view/20590>. Acesso em: 17 dez. 2015.

ABRAMOWICZ, A. Educação infantil e a escola fundamental de 9 anos. Olhar de professor, Ponta Grossa, n. 9, v. 2, p. 317-325, 2006. Disponível em: <http://revistas2.uepg. br/index.php/olhardeprofessor/article/view/1467>. Acesso em: 17 dez. 2015.

ABRAMOWICZ, A.; OLIVEIRA, F. de. Infância, raça e paparicação. Educação em Revista, Belo Horizonte, v. 26, n. 2, p. 209-226, ago. 2010. Disponível em: <http://www. scielo.br/pdf/edur/v26n2/a10v26n2.pdf>. Acesso em: 17 dez. 2015.

ALMEIDA, M. J. de. Investigação visual a respeito do outro. ETD - Educação Temática Digital. Campinas, v. 9, n. 1, p. 266-328, dez. 2007. Disponível em: <http://www.ssoar. 
info/ssoar/bitstream/handle/document/7332/ssoar-etd-2007-1-almeida-investigacao visual_a_respeito_do.pdf?sequence=1. Acesso em: $17 \mathrm{dez} .2015$.

AQUINO, M. A.; SANTANA, S. R. de; SANTANA, L. K. R. de; SILVA JÚNIOR, J. F. da. Temas sobre o/a negro/a: uma análise da produção de conhecimento no curriculum lattes. Revista da ABPN, v. 5, n. 9, p. 172-187, nov. 2012-fev. 2013,. Disponível em: $<$ http://www.abpn.org.br/Revista/index.php/edicoes/article/view/345/249>. Acesso em: 17 dez. 2015.

ARTILES, A. J.; KOZOLESKI, E. B.; GONZALES, T. Para além da sedução da educação inclusiva nos Estados Unidos: confrontando o poder, construindo uma agenda histórico-cultural. Revista Teias, v. 12, n. 24, p. 285-308, jan./abr. 2011. Movimentos sociais processos de inclusão e educação. Disponível em: <http://www.periodicos.proped.pro. br/index.php/revistateias/article/view/820>. Acesso em: 17 dez. 2015.

BONETI, L. W. Etnocentrismo, cultura e políticas educacionais. Cadernos de Pesquisa: Pensamento Educacional (Curitiba. Impresso), v. 4, p. 161-180, 2010. Disponível em: $<$ http://documents.tips/documents/etnocentrismo-cultura-e-politicas-educacionais.html $>$. Acesso em: 17 dez. 2015.

CARVALHO, M. Quem são os meninos que fracassam na escola? Cadernos de Pesqui$s a$, v. 34, n. 121, p. 11-40, jan./abr. 2004. Disponível em: <http://www.scielo.br/pdf/cp/ v34n121/a02n121.pdf>. Acesso em: 17 dez. 2015.

CARVALHO, M. Quem é negro, quem é branco: desempenho escolar e classificação racial de alunos. Revista Brasileira de Educação, n. 28, jan./fev./mar./abr. 2005. Disponível em: <http://www.scielo.br/pdf/rbedu/n28/a07n28>. Acesso em: 17 dez. 2015.

COSTA, R. de A.; SANTOS, T. R. L. dos. Representações sociais de professores de educação infantil sobre a criança negra. Revista de Administração Educacional, Recife, v. 1, n. 2, p. 115-138, jul./dez. 2014. Disponível em: <http://revista.administracaoeducacional.com.br/artigos/09_20142.pdf> Acesso em: 17 dez. 2015.

CRUZ, T. M. Espaço escolar e discriminação: significados de gênero e raça entre crianças. Educação em Revista, Belo Horizonte, v. 30, n. 1, p. 157-188, mar. 2014. Disponível em: <http://www.scielo.br/scielo.php?script=sci_arttext\&pid=S0102$-46982014000100007 \& \operatorname{lng}=$ pt\&nrm=iso\&tlng=pt>. Acesso em: $17 \mathrm{dez} .2015$.

FERNANDES, R. L. da S.; NAZARETH, H. D. G.; REIS, M. A. G. de S. Negritudes e aprendizagem cotidiana. Revista África e Africanidades, ano I, n. 3, nov. 2008. Disponível em: $<$ http://www.africaeafricanidades.com.br/documentos/Negritudes_e_aprendizagem. pdf>. Acesso em: 17 dez. 2015.

FERRARI, A. "Eles me chamam de feia, macaca, chata e gorda. Eu fico muito triste" Classe, raça e gênero em narrativas de violência na escola. Instrumento: R. Est. Educ. Juiz de Fora, v. 12, n. 1, jan./jun. 2010. Disponível em: <https://instrumento.ufjf.emnuvens. com.br/revistainstrumento/article/view/468/436>. Acesso em: 17 dez. 2015. 
FERRARO, A. R.; OLIVEIRA, J. de. Gênero, cor/raça e níveis de letramento em Santa Catarina e Alagoas: um experimento com base em microdados do censo 2000. Perspectiva, v. 27, n. 1, p. 249-271, jan.-jun, 2009 Disponível em: $<$ https://periodicos.ufsc. br/index.php/perspectiva/article/view/2175-795X.2009v27n1p249/12300>. Acesso em: 17 dez. 2015.

FRANCISCO JÚNIOR, W. E. Educação Antirracista: reflexões e contribuições possíveis do ensino de ciências e de alguns pensadores. Ciência \& Educação, v. 14, n. 3, p. $397-$ 416, 2008. Disponível em: <http://www.redalyc.org/articulo.oa?id=251019504003>. Acesso em: 17 dez. 2015.

GLASS, R. D. Entendendo raça e racismo: por uma educação racialmente crítica e antirracista. Revista Brasileira de Estudos Pedagógicos. Brasília, v. 93, n. 235, p. 883-913, set./dez., 2012. Disponível em: <http:/www.scielo.br/scielo.php?pid=S2176$-66812012000400017 \&$ script=sci_abstract\&tlng=pt>. Acesso em: 17 dez. 2015.

GUIMARÃES, A. S. A. Como trabalhar com "raça" em sociologia. Educação e Pesquisa, São Paulo, v. 29, n. 1, p. 93-107, jan./jun. 2003. Disponível em: <http:/www.scielo.br/ scielo.php?script $=$ sci_abstract\&pid $=\mathrm{S} 1517-97022003000100008 \& \operatorname{lng}=$ pt\&nrm $=$ iso \&t $\operatorname{lng}=\mathrm{pt}>$. Acesso em: $17 \mathrm{dez} .2015$.

GUIMARÃES, C.A. S. A intersecção entre raça e pobreza na trajetória escolar de jovens negros. Roteiro, Joaçaba, v. 39, n. 2, p. 515-542, jul./dez. 2014. Disponível em: $<$ http:// editora.unoesc.edu.br/index.php/roteiro/article/view/4079>. Acesso em: 17 dez. 2015.

LEMOS, F. C. S.; CRUZ; F. F. da; SOUZA, G. S. Medicalização da produção da diferença e racismo em algumas práticas educativas pacificadoras. Revista Profissão Docente, Uberaba, v. 14, n. 30, p. 7-20, jan.-jun. 2014. Disponível em: <http://www.revistas.uniube. br/index.php/rpd/article/view/851/1097>. Acesso em: 17 dez. 2015.

PEREIRA, J. H. do V. Violência simbólica em escolas de fronteira: em questão as diferenças étnico-culturais. Educação e linguagem, v. 14. n. 23/24, jan-dez 2011. Disponível em: <https:/www.metodista.br/revistas/revistas-ims/index.php/EL/article/ viewArticle/2909>. Acesso em: 17 dez. 2015.

PICCOLO, G. M. Caminhos da exclusão: análise do preconceito em sua manifestação nos jogos infantis. Movimentos, Porto Alegre, v. 16, n. 1, p. 191-207, jan./mar. 2010. Disponível em: <http://seer.ufrgs.br/index.php/Movimento/article/view/8183>. Acesso em: 17 dez. 2015.

PINHO, V. A.; SANTOS, S. L. dos. Um estudo sobre crianças negras no contexto da educação infantil. Rev. Fac. Educ., Univ. do Estado do Mato Grosso, v. 22, ano 12, n. 2, p. 81-98, jul./dez. 2014. Disponível em: <http://www2.unemat.br/revistafaed/content/ vol/vol_22/artigo_22/81_98.pdf>.Acesso em: 17 dez. 2015.

ROACH, E. F. F. Clases, gêneros y razas em eles pejo del saber escolar. Atos de Pesquisa em Educação, PPGEME FURB, v. 6, n. 2, p. 403-426. maio/ago. 2011. Disponível em: $<$ http://proxy.furb.br/ojs/index.php/atosdepesquisa/article/view/2577>. Acesso em: 17 dez. 2015. 
ROSEMBERG, F. Educação infantil e relações raciais: A tensão entre igualdade e diversidade. Cadernos de Pesquisa, v. 44, n. 153, p. 742-759, jul./set. 2014. Disponível em: $<$ http:/www.scielo.br/scielo.php?script=sci_arttext\&pid=S0100-15742014000300013>. Acesso em: 17 dez. 2015.

ROSEMBERG, F.; ROCHA, E. J. da. Autodeclaração de cor e/ou raça entre escolares paulistanos (as). Cadernos de Pesquisa, v. 37, n. 132, p. 759-799, set./dez. 2007. Disponível em: <http://www.scielo.br/scielo.php?script=sci_arttext\&pid $=\mathrm{S} 0100-15742007000300012>$. Acesso em: $17 \mathrm{dez} .2015$.

SCHNEIDER, C. I.; BIRANOSKI, C. Cidade de Deus entre a história e a literatura: problemática racial no Rio de Janeiro (1960-1980). Cad. de Pesq. Interdisc. em Ciências Humanas, Florianópolis, Santa Catarina, v. 15, n. 106, p. 27-47, jan./jun. 2014. Disponível em: <https://periodicos.ufsc.br/index.php/cadernosdepesquisa/article/view/1984-8951.2014v15n106p27>. Acesso em: 17 dez. 2015.

SILVA, A. dos R.; TEIXEIRA, M. de P. O processo educacional brasileiro: um breve olhar ético e histórico acerca do sujeito afrodescendente. Educação em Foco, UEMG, Belo Horizonte, ano 12, n. 14, p. 105-121, 2009. Disponível em: <http:/www.uemg. br/openjournal/index.php/educacaoemfoco/article/view/86>. Acesso em: 17 dez. 2015.

SILVA, C. R. da. Vivências de um professor negro na educação infantil. Revista África e Africanidades, ano 4, n. 16 e 17, fev./maio 2012. Disponível em: <http://www.africaeafricanidades.com.br/documentos/16-17_03.pdf>. Acesso em: 17 dez. 2015.

SILVA, E. A. Prática docente de professoras negras acerca da questão étnico racial sob a ótica de ex-alunos. Cadernos da Pedagogia, ano 2, v. 2, n. 4, p. 45-66. ago./dez. 2008. Disponível em: <http://www.cadernosdapedagogia.ufscar.br/index.php/cp/article/ viewFile/101/58>. Acesso em: 17 dez. 2015.

SILVA, F. C.; PALUDO, K. I. Racismo implícito: um olhar para a educação infantil. Revista África e Africanidades. - ano IV - n. 14/15 - agosto-novembro. 2011 - ISSN 1983-2354. Disponível em: <http://www.africaeafricanidades.com.br/documentos/14152011-19.pdf>. Acesso em: 17 dez. 2015.

SILVA, K.; MORAIS, S. S. Tendências e tensões de sociabilidade de estudantes dos Palop em duas universidades brasileiras. Pro-Posições, Campinas, v. 23, n. 1(67), p. 163-182, jan/abr. 2012. Disponível em: <http://www.scielo.br/pdf/pp/v23n1/11.pdf>. Acesso em: 17 dez. 2015.

SILVA, M. Linhares da Biopolítica e espaço escolar: subjetividade e racismo no Brasil. Revista de Educação Horizontes, Itatiba, v. 32, n. 2, p. 111-122, jan./jun.2014. Disponível em: <https://revistahorizontes.usf.edu.br/horizontes/article/view/94/49>. Acesso em: 17 dez. 2015.

SILVA, N. da. Tentativas de desconstrução do racismo e preconceitos: um diálogo entre o Norte e o Sul do século XXI. Acolhendo a Alfabetização nos países de Língua Portuguesa. Revista Eletrônica Acolhendo a Alfabetização nos Países de Língua Portuguesa, v. 5, n. 
10, p. 123-144, 2011. Sítio Oficial: <http:/www.acoalfaplp.net>. Disponível em: $<$ http:// www.revistas.usp.br/reaa/article/view/11580>. Acesso em: 17 dez. 2015.

SOARES, J. F.; ALVES, M. T. G. Desigualdades no sistema brasileiro de educação básica. Educação e Pesquisa, São Paulo, v. 29, n. 1, p. 147-165, jan./jun. 2003. Disponível em: <http://www.scielo.br/scielo.php?script=sci_abstract\&pid=S1517-97022003000100011\&lng=pt\&nrm=iso\&tlng=pt>. Acesso em: 17 dez. 2015.

SOUSA, P. F. de; RIBEIRO, C. A. C.; CARVALHAES, F. Desigualdade de oportunidades no Brasil: considerações sobre classe, educação e raça. Revista Brasileira de Ciências Sociais, v. 25, n. 73, p. 72-97, jun. 2010. Disponível em: <http:/www.scielo.br/pdf/ rbcsoc/v25n73/v25n73a05.pdf $>$. Acesso em: 17 dez. 2015.

SOUZA, A. S. de. Racismo institucional: para compreender o conceito. Revista da ABPN, v. 1, n. 3, p. 77-87, nov. 2010-fev. 2011. Disponível em: <http://www.abpn.org.br/Revista/ index.php/edicoes/article/view/39/82>. Acesso em: 17 dez. 2015.

VALENTE, A. L. Ação afirmativa. Relações raciais e Educação Básica. Revista Brasileira de Educação, n, 28, p. 62-75, jan./fev./mar./abr. 2005. Disponível em: <http://www. scielo.br/pdf/rbedu/n28/a06n28.pdf>. Acesso em: 17 dez. 2015.

YANNOULAS, S. C.; ASSIS, S. G.; FERREIRA, K. M. Educação e pobreza: limiares de um campo em (re)definição. Revista Brasileira de Educação, v. 17, n. 50, p. 329-351, maio-ago. 2012. Disponível em: $<$ http://www.redalyc.org/articulo.oa?id=27523620005>. Acesso em: 17 dez. 2015.

\section{Teses e dissertações analisadas}

ABREU, A. R. dos S. Relações sociais em uma escola pública municipal de altos, Piauí: um estudo das realidades de alunas/os afrodescendentes e as professoras. 2014. Dissertação (Mestrado em Educação) - Centro de Ciências da Educação, Universidade Federal do Piauí, 2014. Disponível em: <http://leg.ufpi.br/subsiteFiles/ppged/arquivos/files/ DISSERTA \%C3\%87\%C3\%83O\%20FINAL\%2014_05\%20ANTONIA\%20REGINA. pdf>. Acesso em: 23 nov. 2017.

ALEXANDRE, I. J. Relações raciais: o explícito e o implícito nas interações entre alunos em uma escola pública. 2006. Dissertação (Mestrado em Educação) - Instituto de Educação, Universidade Federal de Mato Grosso, Cuiabá, 2006. Disponível em: $<$ http:// hdl.handle.net/123456789/1683>. Acesso em: 23 nov. 2017.

ALGARVE, V. A. Cultura negra na sala de aula: pode um cantinho de africanidades elevar a autoestima de crianças negras e melhorar o relacionamento entre crianças negras e brancas? 2004. Dissertação de mestrado. Universidade Federal de São Carlos, 2004. Disponível em: <https://repositorio.ufscar.br/bitstream/handle/ufscar/2661/DissVAA. pdf? sequence $=1>$. Acesso em: 23 nov. 2017.

ALVES, L. Significados de ser branco: a brancura no corpo e para além dele. 2010. Dissertação (Mestrado - Programa da Pós-Graduação em Educação - Área de concentração: 
Sociologia da Educação) - Faculdade de Educação da Universidade de São Paulo, 2010. Disponível em: <http:/www.teses.usp.br/teses/disponiveis/48/48134/tde-14062010153851/pt-br.php>. Acesso em: 23 nov. 2017.

ALVES, A. M. A inserção da temática racial nas séries iniciais do Ensino Fundamental em uma escola da rede pública municipal de Campo Grande. 2007. Dissertação (Mestrado em Educação). Universidade Católica de Brasília. Brasília, 2007. Disponível em: <http://site.ucdb.br/public/md-dissertacoes/7979-a-insercao-da-tematica-racial-nas-series-iniciais-do-ensino-fundamental-em-uma-escola-da-rede-publica-municipal-de-campo-grande.pdf>. Acesso em: 23 nov. 2017.

BATISTA, M. V. O.A. Giz de cor: um olhar de professores negros sobre as relações raciais na escola pública. 2008. Dissertação (Mestrado em Educação e Formação) - Universidade Católica de Santos, Santos, 2008. Disponível em: <http://biblioteca.unisantos.br:8181/ handle/tede/128\#preview-link0>. Acesso em: 23 nov. 2017.

BONILHA, T. M. O não lugar do sujeito negro na educação brasileira. 2012. Dissertação (Mestrado em Educação). Universidade Estadual de Campinas. Campinas, 2012. Disponível em: <http://repositorio.unicamp.br/handle/REPOSIP/250937>. Acesso em: 23 nov. 2017.

BOUÇAS, S. R. da S. B. Valores e sentimentos subjacentes à discriminação racial: um estudo na perspectiva dos Modelos Organizadores do Pensamento. 2011. Dissertação (Mestrado em Educação) - Universidade de São Paulo, São Paulo, 2011. Disponível em: <http:// biblioteca.portalbolsasdeestudo.com.br/link/?id=2370490>. Acesso em: 23 nov. 2017.

CALADO, M. da G. Escola e enfrentamento do racismo: as experiências das professoras ganhadoras do Prêmio Educar para a Igualdade Racial 2013. 2013. Tese (Doutorado em Educação) - USP/FEUSP, 2013. Disponível em: <http://www.teses.usp.br/teses/disponiveis/48/48134/tde-25032014-133053/pt-br.php>. Acesso em: 23 nov. 2017.

CLEUMA, M. C. de A. Racismo na escola: um estudo da linguagem racista e de suas implicações no contexto escolar da UEB. Gonçalves Dias de Açailândia - MA. 2013. Dissertação (Mestrado em Educação) - Universidade Federal do Maranhão. Maranhão, 2013. Disponível em: <https://tedebc.ufma.br/jspui/handle/tede/260>. Acesso em: 23 nov. 2017.

CONCEIÇÃO, B. H. T. O Programa de Superação das Desigualdades Raciais de Mato Grosso do Sul e Educação. 2003. Dissertação (Mestrado em Educação). Universidade Federal do Mato Grosso do Sul. Mato Grosso do Sul, 2003. Disponível em: $<$ http:// repositorio.cbc.ufms.br:8080/jspui/browse?type $=$ author $\&$ value $=$ Concei $\% \mathrm{C} 3 \% \mathrm{~A} 7 \% \mathrm{C}$ 3\%A3o\%2C+Beatriz+Helena+Teixeira>. Acesso em: 23 nov. 2017.

CONSTANTINO, F. de L. Comunidades de aprendizagem: contribuições da perspectiva dialógica para a construção positiva das identidades das crianças negras na escola. 2010. Dissertação (Mestrado em Educação) - Universidade Federal de São Carlos. São Carlos, 2010. Disponível em: <https://repositorio.ufscar.br/handle/ufscar/2543>. Acesso em: 23 nov. 2017. 
COSTA, R. S. de. A criança negra: as representações sociais de professores de educação infantil. 2013. Dissertação (Mestrado em Educação) Universidade Estadual do Pará. Pará, 2013. Disponível em: <http://www.educampoparaense.com.br/publicacao/a-crianca-negra-as-representacoes-sociais-de-professores-de-educacao-infantil>. Acesso em: 23 nov. 2017.

CRUZ, A. C. J. da. Os debates do significado de educar para as relações étnico-raciais na educação brasileira. 2010. Dissertação (Mestrado em Educação) - Universidade Federal de São Carlos. São Carlos, 2010. Disponível em: <https://repositorio.ufscar.br/ handle/ufscar/2519>. Acesso em: 23 nov. 2017.

CRUZ, A. C. J. da. Antirracismo e educação: uma análise das diretrizes normativas da UNESCO. 2014. Tese (Doutorado em Educação) - Universidade Federal de São Carlos. São Carlos, 2014. Disponível em: <https://repositorio.ufscar.br/handle/ufscar/2338>. Acesso em: 23 nov. 2017.

DEMARZO, M. A. D. Educação das relações étnico-raciais: aprendizagens e experiências de professoras em São Carlos-SP. 2009. Dissertação (Mestrado em Educação) - Universidade Federal de São Carlos. São Carlos, 2009. Disponível em: < https://repositorio. ufscar.br/handle/ufscar/2679>. Acesso em: 23 nov. 2017.

FEITOSA, C. F. J. “Aqui tem racismo!'”: um estudo das representações sociais e das identidades das crianças negras. 2012. Dissertação (Mestrado em Educação) - Universidade Estadual de Campinas. Campinas, 2012. Disponível em: $<$ http://repositorio.unicamp.br/ jspui/handle/REPOSIP/250918>. Acesso em: 23 nov. 2017.

FIRMO, Y. de O. O Psicodrama: uma estratégia contra o racismo. 2010. Dissertação (Mestrado em Educação) - Universidade Federal de Mato Grosso. Cuiabá, 2010. Disponível em: <http://www.dominiopublico.gov.br/pesquisa/DetalheObraForm. do?select_action=\&co_obra=179526. Acesso em: 23 nov. 2017.

FOSTER, E. da L. S. Racismo e movimentos instituintes na escola. 2004. Tese (Doutorado em Educação) - Universidade Federal Fluminense. Niterói, 2004. Disponível em: $<$ http://www.bdtd.ndc.uff.br/tde_busca/arquivo.php?codArquivo=246>. Acesso em: 23 nov. 2017.

GOMES, M. R. L. Relações raciais no cotidiano escolar: percepções de famílias no município de Cuiabá - entre o visível e o invisível. 2008. Dissertação (Mestrado em Educação) - Universidade Federal de Mato Grosso. Cuiabá, 2008. Disponível em: $<$ http://www.dominiopublico.gov.br/pesquisa/DetalheObraForm.do?select_action=\&co obra $=121864>$. Acesso em: 23 nov. 2017.

GONÇALVES, V. L. S. Tia, qual é o meu desempenho: percepções de professores sobre o desempenho escolar de alunos negros. 2007. Dissertação (Mestrado em Educação) Universidade Federal de Mato Grosso. Cuiabá, 2007. (Coleção Educação e Relações Raciais, v. 7)

JESUS, L. H. de. Trajetórias de vida e estudo de alunos negros do Ensino Médio da cidade de Tapurah -MT. 2005. Dissertação (Mestrado em Educação) - Universidade 
Federal de Mato Grosso. Cuiabá, 2005. Disponível em: <http://livros01.livrosgratis. com.br/cp043511.pdf>. Acesso em: 23 nov. 2017.

KABEYA, R. B. A. Alunas negras e trajetórias de escolarização: perfil da EJA. 2010. Dissertação (Mestrado em Educação) - Universidade Federal de Mato Grosso. Cuiabá, 2010. Disponível em: < http://www.dominiopublico.gov.br/pesquisa/DetalheObraForm. do?select_action=\&co_obra=179587>. Acesso em: 23 nov. 2017.

LOURDES, J. da S. Faculdade da Cidadania Zumbi dos Palmares: "O quilombo de século XXI"? 2010. Dissertação (Mestrado em Educação) - Universidade Metodista de São Paulo. São Paulo, 2010. Disponível em: <http://tede.metodista.br/jspui/handle/ tede/1162>. Acesso em: 23 nov. 2017.

MACÊDO, M. D. de L. Resistência cultural de estudantes negros da roça, nas escolas públicas de Santa Bárbara - BA. 2011. Dissertação (Mestrado em Educação) - Universidade do Estado da Bahia. Salvador, 2011. Disponível em: <http://www.cdi.uneb.br/ pdfs/educacao/2011/maria_dalva_de_lima_macedo.pdf >.Acesso em: 23 nov. 2017.

MACÊDO, M. D. de L. Tradição oral afro-brasileira e escola: (des)encontros na encruzilhada: uma reflexão a partir do município de Santa Bárbara - BA. 2004. Dissertação (Mestrado em Educação) - Universidade do Estado da Bahia. Salvador, 2004. Disponível em: <http://www.cdi.uneb.br/site/wp-content/uploads/2016/01/marluce_de_lima_macedo.pdf>. Acesso em: 23 nov. 2017.

MACHADO, S. M. Uma cartografia da produção do racismo no currículo vivido no cotidiano escolar do ensino fundamental. 2011. 185 f. Dissertação (Mestrado em Educação) - Universidade Federal do Espírito Santo, Vitória, 2011. Disponível em: <http:// repositorio.ufes.br/handle/10/6020>. Acesso em: 23 nov. 2017.

MACHADO, L. H de A. Professores negros, experiências de discriminação, de racismo e pedagogias anti-racistas. 2007. Dissertação (Mestrado em Educação) - Universidade Federal de São Carlos. São Carlos, 2007. Disponível em: <https://repositorio.ufscar.br/ bitstream/handle/ufscar/2569/3360.pdf?sequence=1>. Acesso em: 23 nov. 2017.

MONTEIRO, E. S. Educação e discriminação racial: convergências e divergências na percepção de famílias negras e brancas no município de Cuiabá. 2008. Dissertação (Mestrado em Educação) - Universidade Federal de Mato Grosso. Cuiabá, 2008. Disponível em: <http://livros01.livrosgratis.com.br/cp075170.pdf>. Acesso em: 23 nov. 2017.

MOURA, D. C. de. Leitura e identidades étnico-raciais: reflexões sobre práticas discursivas na educação de jovens e adultos. 2010. Tese (Doutorado em Educação) - Universidade Federal de Pernambuco. Pernambuco, 2010. Disponível em: $<$ http://repositorio.ufpe.br/ handle/123456789/3784>. Acesso em: 23 nov. 2017.

NASCIMENTO, L. G. Aqui todos são iguais!: Uma análise sobre as relações étnico-raciais em escolas municipais do Rio de Janeiro. 2012. Dissertação (Mestrado em Educação) - UNIRIO, 2012. Disponível em: <https://docs.google.com/file/d/0B-sE2Ar37CoNR3N2VS0zcFpuWXc/edit>. Acesso em: 23 nov. 2017. 
NETO, J. E. C. Escola: possibilidades e desafios da inclusão autônoma do afro-brasileiro a partir de categorias revisitadas da modernidade. 2006. Dissertação (Mestrado em Educação) - Universidade do Vale do Rio do Sinos. São Leopoldo, 2006. Disponível em: <http:// www.repositorio.jesuita.org.br/handle/UNISINOS/1905>. Acesso em: 23 nov. 2017.

NEVES, I. S. Relações étnico-raciais na educação: concepções elaboradas por professores(as) e estudante(s) da Educação de Jovens e adultos da escola Dra Nise da Silveira após a promulgação da Lei 10.639/03. 2010. Dissertação (Mestrado em Educação) - Universidade Federal de Alagoas. Alagoas, 2010. Disponível em: <http://www. ufal.edu.br/unidadeacademica/cedu/pos-graduacao/mestrado-e-doutorado-em-educacao/ dissertacoes/2008/irani-da-silva-neves/view>. Acesso em: 23 nov. 2017.

OLIVEIRA, S. M. de. A formação de atitudes racistas em uma unidade de educação infantil em Belo Horizonte: o que as rotinas e as interações entre as crianças nos revelam. 2012. 157 f. Dissertação (Mestrado em Educação) - Faculdade de Educação, Pontifícia Universidade Católica de Minas Gerais, Belo Horizonte, 2012.

PAULINO, C. A. Acesso diferenciado de alunos brancos e negros. 2013. Dissertação (Mestrado em Educação) - Universidade Federal de Mato Grosso. Cuiabá, 2013.

RAMOS, A. O. Práticas de discriminação racial nos anos iniciais do Ensino Fundamental: sentidos de professoras. 2015. Dissertação (Mestrado em Educação) - Universidade Estadual do Sudoeste da Bahia. Vitória da Conquista, 2015. Disponível em: $<$ http:// www2.uesb.br/ppg/ppged/wp-content/uploads/2016/09/Dissert_AlineOliveiraRamos. pdf $>$. Acesso em: 23 nov. 2017.

RODRIGUES, A. B. Algumas contribuições para um Programa de Estudos Afro-Brasileiros. 2007. Dissertação (Mestrado em Educação) - Universidade Federal de São Carlos. São Carlos, 2007. Disponível em: <https://repositorio.ufscar.br/handle/ ufscar/2570>. Acesso em: 23 nov. 2017.

RODRIGUES, R. M. M. Educação das relações raciais no Distrito Federal: desafios da gestão. 2010. Dissertação (Mestrado em Educação) - Universidade de Brasília, Brasília, 2010. Disponível em: <http://repositorio.unb.br/handle/10482/6943>. Acesso em: 23 nov. 2017.

ROSA, A. S. Imaginário, corpo e caneta: matriz afro-brasileira em educação de jovens e adultos. 2009. Dissertação (Mestrado em Educação) - Universidade de São Paulo. São Paulo, 2009. Disponível em: <http://www.teses.usp.br/teses/disponiveis/48/48134/ tde-23032010-144503/pt-br.php>. Acesso em: 23 nov. 2017.

SANTANA, L. A. Histórias cruzadas: leitura de mulheres negras da EJA. 2008. Dissertação (Mestrado em Educação) - Universidade do Estado da Bahia. Salvador, 2008. Disponível em: <http://www.cdi.uneb.br/site/wp-content/uploads/2016/01/leidinalva_amorim_santana_das_merces.pdf $>$. Acesso em: 23 nov. 2017.

SANTANA, M. A. Relações raciais no cotidiano escolar: percepções de diretoras e alunos de duas escolas municipais de Cuiabá. 2012. Dissertação (Mestrado em Educação) - Universidade Federal de Mato Grosso. Cuiabá, 2012. 
SANTIAGO, F. "O meu cabelo é assim... igualzinho o da bruxa, todo armado": hierarquização e racialização das crianças pequenininhas negras na educação infantil. 2014. Dissertação (Mestrado em Educação) - Universidade Estadual de Campinas. Campinas, 2014. Disponível em: <http://www.repositorio.unicamp.br/handle/REPOSIP/319164>. Acesso em: 23 nov. 2017.

SANTOS, S. R. dos. Tia, a Senhora é Negra Porque Quer: narrativas que abordam memória e identidades. 2011. Dissertação (Mestrado em Educação) - Centro de Educação e Humanidades, Universidade do Estado do Rio de Janeiro. Rio de Janeiro, 2011. Disponível em: <http://www.bdtd.uerj.br/tde_busca/arquivo.php?codArquivo=3720>. Acesso em: 23 nov. 2017.

SANTOS, J. N. dos. Preconceito racial em foco: uma análise das relações estabelecidas entre crianças negras e não negras na educação infantil. 2013. Dissertação (Mestrado em Educação) - Pontifícia Universidade Católica de São Paulo. São Paulo, 2013. Disponível em: <https://tede2.pucsp.br/handle/handle/10404>. Acesso em: 23 nov. 2017.

SANTOS, M. A. dos. Representações de gênero e raça no Ensino Fundamental: a construção da identidade do ser "menina negra" e do ser "menino negro". 2008. Dissertação (Mestrado em Educação) - Universidade do Estado da Bahia. Salvador, 2008. Disponível em: <http://www.cdi.uneb.br/pdfs/educacao/2009/marluse_arapiraca_dos_santos.pdf $>$. Acesso em: 23 nov. 2017.

SANTOS, R. C. O. dos. Aluno negro em sala branca: representações sociais de aluno/a sobre relações étnico-raciais afetadas no contexto educativo. 2011. Dissertação (Mestrado em Educação) - Universidade do Estado da Bahia. Salvador, 2011. Disponível em: $<$ http://www.cdi.uneb.br/pdfs/educacao/2011/roberto_carlos_oliveira_dos_santos.pdf $>$. Acesso em: 23 nov. 2017.

SANTOS, S. E. dos. As crianças (in)visíveis nos discursos políticos da educação infantil: entre imagens e palavras. 2014. Tese (Doutorado em Educação) - Universidade Estadual de Campinas. Campinas, 2014.

SILVA, J. B. A. da. As/os docentes de história da escolarização básica e a (des/re) construção das identidades negras. 2013. Dissertação (Mestrado em Educação) - Universidade Católica de Brasília. Brasília, 2013. Disponível em: <http://site.ucdb.br/public/ md-dissertacoes/11099-jose-bonifacio-alves-da-silva.pdf>. Acesso em: 23 nov. 2017.

SILVEIRA, A. C. Raça e desempenho escolar: uma análise comparativa do desempenho de crianças negras e brancas em escolas integrantes do Projeto GERES em Salvador - BA. 2012. Dissertação (Mestrado em Educação) - Universidade Federal da Bahia. Salvador, 2012. Disponível em: <http://www.repositorio.ufba.br/ri/handle/ri/12976>. Acesso em: 23 nov. 2017.

SOARES, L. N. Relações étnico-raciais nas práticas educativas da educação infantil: ouvindo crianças e adultos. 2013. Dissertação (Mestrado em Educação) - Universidade do Estado de Minas Gerais. Belo Horizonte, 2013. Disponível em: <http://www.ppgeduc. uemg.br/wp-content/uploads/2016/06/TD9141847882.pdf>. Acesso em: 23 nov. 2017. 
SOUSA, K. C. S. Estereótipos étnicos nas representações de crianças escolarizadas em São Luis do Maranhão. 2009. Dissertação (Mestrado em Educação) - Universidade Federal do Maranhão. Maranhão, 2009. Disponível em: <http://bdtd.ibict.br/vufind/ Record/UFMA_17168215cec240afc3d89965304bad1b>. Acesso em: 23 nov. 2017.

SOUZA, A. de M. Representações de adolescentes brancos sobre jovens negras, alunos de uma escola pública no município de Araputanga - MT. 2008. Dissertação (Mestrado em Educação) - Universidade Federal de Mato Grosso. Cuiabá, 2008. Disponível em: $<$ http://livros01.livrosgratis.com.br/cp078708.pdf>. Acesso em: 23 nov. 2017.

SOUZA, M. E. V. Culturas, realidades e preconceito racial no cotidiano escolar. 2003. Tese (Doutorado em Educação) - Universidade Estadual de Campinas. Campinas, 2003. Disponível em: <http://repositorio.unicamp.br/bitstream/REPOSIP/253480/1/ Souza,M.E.V.pdf $>$. Acesso em: 23 nov. 2017.

TEIXEIRA, C. S. Conselhos escolares do Paranoá/DF: a participação dos atores sociais negros. 2012. Dissertação (Mestrado em Educação) - Universidade de Brasília, Brasília, 2012. Disponível em: <http://repositorio.unb.br/handle/10482/13383>. Acesso em: 23 nov. 2017.

TELES, C. de P. Representações sociais sobre as crianças negras na educação infantil: mudanças e permanências a partir da prática pedagógica de uma professora. 2010. Dissertação. Universidade de São Paulo - Faculdade de Educação, 2010. Disponível em: <http://www.teses.usp.br/teses/disponiveis/48/48134/tde-22062010-124314/pt-br. php>. Acesso em: 23 nov. 2017.

TRINIDAD. C. T. Identificação étnico-racial na voz de crianças em espaços de educação infantil. 2011. Tese (Doutorado em Educação) - Pontifícia Universidade Católica de São Paulo. São Paulo, 2011. Disponível em: <https://tede2.pucsp.br/handle/handle/15994>. Acesso em: 23 nov. 2017.

ZANDONA, E. P. Trajetória escolar de jovens negros do Ensino Médio: perspectivas em relação ao Ensino Superior. 2008. Dissertação (Mestrado em Educação) - Universidade Federal de Mato Grosso. Cuiabá, 2008. Disponível em: $<\mathrm{http}: / /$ www.dominiopublico. gov.br/pesquisa/DetalheObraForm.do?select_action $=\&$ co_obra $=127734>$. Acesso em: 23 nov. 2017.

Texto recebido em 29 de dezembro de 2017. Texto aprovado em 30 de dezembro de 2017. 